\title{
The use of spatial tools in the study of Schistosoma mansoni and its intermediate host snails in Brazil: a brief review
}

\author{
Andrea Gazzinelli ${ }^{1}$, Helmut Kloos ${ }^{2}$ \\ ${ }^{1}$ Escola de Enfermagem, Universidade Federal de Minas Gerais, Belo Horizonte, Brazil; ${ }^{2}$ Department of \\ Epidemiology and Biostatistics, University of California, San Francisco, USA
}

\begin{abstract}
The rapidly increasing number of spatial studies and the complexity of schistosomiasis transmission dynamics in Brazil indicate that surveillance and control programmes can benefit from the spatial approach, not only in areas susceptible to the introduction and establishment of new transmission foci but also in areas experiencing declines in schistosomiasis transmission. Several additional areas amenable to, or requiring, spatial research are identified. This paper reviews spatial studies of schistosomiasis in Brazil with a focus on the application of spatial tools in epidemiological, disease ecological, control and several additional areas in schistosomiasis research.
\end{abstract}

Keywords: schistosomiasis, Biomphalaria spp., geographical information system, mapping, Brazil.

\section{Introduction}

Computer-assisted mapping and spatial analysis of infectious diseases have seen major advances in recent years. The appropriateness of using geographical information system (GIS), global positioning system (GPS) and remote sensing (RS) tools in the study of schistosomiasis and other vector-borne diseases and progress in their application in epidemiological studies and control programmes have been reviewed by Malone et al. (2001a). The dynamic nature of vector-borne diseases and the need for rapid decision making, as well as their intimate linkage to the physico-biotic and human environment, demonstrated by mathematical modeling, have facilitated the development of more accurate and rapid spatial techniques than those possible with traditional manual mapping and spatial analysis methods (Morel, 2001). Heterogeneity in both intermediate host snail

Corresponding author:

Andrea Gazzinelli

Escola de Enfermagem

Universidade Federal de Minas Gerais

Belo Horizonte, Brazil

Tel. +55 31 32489827; Fax +55 3132489830

E-mail: andreag@enf.ufmg.br distribution and human behaviour associated with risk of infection (water contact behaviour) are instrumental in determining schistosomiasis transmission dynamics (Woolhouse et al., 1991; Brooker and Michael, 2000) and provide many opportunities for spatial studies.

In Brazil, where traditional manual mapping methods had been used to document the spread of schistosomiasis and its intermediate snail hosts since the $19^{\text {th }}$ century (Meira, 1949; Kvale, 1981; Machado, 1982), the use of intermediate level spatial analytic tools predates the arrival of GIS and GPS. Barreto (1993), for example, used a computerized digitizer to plot dots on $\mathrm{x}$ and $\mathrm{y}$ coordinates for individual study households, which he then correlated with socio-economic and epidemiological data to determine schistosomiasis risk factors at the community level. In Branquinha, another town in the hyperendemic northeast of Brazil, Kloetzel (1989) used grid diagrams, which he overlaid on a town map, to identify and spatially correlate poor neighborhoods with high schistosomiasis prevalence. This analysis revealed that infection foci persisted after chemotherapy of all children, indicating the strong link between schistosomiasis and poverty. Computerized spatial studies have been carried out 
during the last 10 years in increasing numbers in the areas of snail distribution, risk of infection, and schistosomiasis control. The rapid increase of spatial studies of schistosomiasis using GIS, GPS and RS tools in Brazil is reflected in the exponential increase in the number of presentations at the biannual schistosomiasis symposia held in this country since the Symposium in Rio de Janeiro in 1999. In 2000 , Brazil became part of a global network of collaborating organizations and individual scientists dedicated to the development of computer-based models suitable for improved control programmes for schistosomiasis and other snail-borne diseases (Malone et al., 2001b).

The objective of this review is to briefly summarize the literature of epidemiological, ecological and intervention studies in Brazil using the spatial approach and to point out opportunities for studies in some understudied areas of schistosomiasis research.

\section{Epidemiological and disease ecological studies}

Spatial studies of risk of schistosomiasis using GIS, GPS and RS tools have proceeded along two main lines, namely description of the distribution of infection or risk of infection and secondly the spatial modeling of infection risk. Descriptive mapping of schistosomiasis has been used to elucidate the heterogeneity of infection and risk of infection at the individual, neighbourhood, and regional levels. Kloos et al. $(1998,2001)$ associated both the presence of a water supply in the household and low socio-economic status with high Schistosoma mansoni infection rates both before and after the installation of a piped water supply in a small rural village in northern Minas Gerais State. This is the only study to map exposure risk based on direct observation of human water-contact patterns in a small rural village in Minas Gerais (Kloos et al., 1998, 2001). Exposure risk in Brazil has traditionally been studied through interviews, which are more costeffective, in a country where private ownership of rural land and water resources causes human water contact patterns to be more dispersed at more sites than in Africa (Kloos et al., 1998, 2006; McClennon et al., 2004).

The recent shift in emphasis, from area-wide schistosomiasis control programmes to more focused interventions targeting high-risk individuals and communities in both highly endemic areas and in low transmission areas (WHO, 2001; Savioli et al., 2004), makes spatial analyses at the local and household levels essential (Brooker and Michael, 2000). In Brazil, several epidemiological studies in Melquiades rural area in Minas Gerais established the crucial role of the household as a risk group in regard to behavioural and infection parameters (Bethony et al., 2001, 2004; Gazzinelli et al., 2001). In Virgem das Graças, another rural area in northern Minas Gerais, distinct spatial patterns of schistosomiasis were noted in a household-based study using a pre-/post-treatment design. Pre-treatment household prevalence and egg counts were highly concentrated in some households and neighbourhoods and inversely related to post-treatment $\operatorname{IgE}$ levels. In the single village with a central water supply, low exposure risk was associated with low pretreatment infection rates (Fig. 1) but did not, like distance from homes to the streams, contribute to the sharp decline of infection rates after chemotherapy (Gazzinelli et al., 2006). These results demonstrate the production and antiparasitic effect of high levels of IgE in S. mansoni infection and their impact on the focality of infection at the household level.

Longitudinal spatial studies using patient data collected by the health services, although underreporting the number of $S$. mansoni infections, has provided some useful information for the planning of control programmes. Most longitudinal epidemiological studies and historical studies of the spatial distribution of hospital admissions and deaths from schistosomiasis in Brazil show a long-term decline (Katz, 1998) but several investigators have also reported increased prevalence for some periods or some areas. In Pernambuco State, for example, the number of hospitalized schistosomiasis cases from the interior of that State and in the São Francisco River Valley increased in 1999 and 2000 after a 


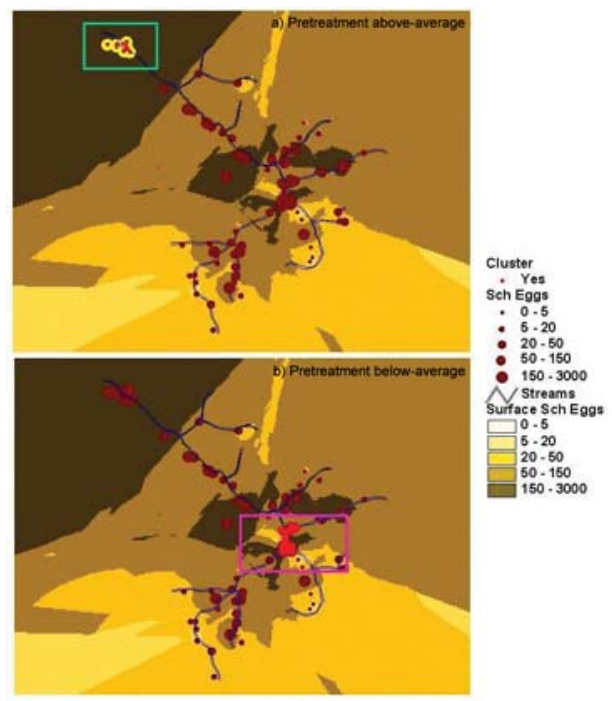

Fig. 1. Schistosoma mansoni egg counts in Virgem das Graças, Brazil. a: pre-treatment above-average counts $(\mathrm{p}=0.001)$; b: below-average counts $(\mathrm{p}=0.005)$.

Source: Gazzinelli et al. (2006).

decline between 1992 and 1998 (Resendes et al., 2005). In Bahia State, no significant changes were noted in the distribution of schistosomiasis at the municipality level between the 1950s and 1980s, even though the overall prevalence had declined from $15.6 \%$ to $9.5 \%$. This decline was not associated with the administration of community-based chemotherapy, and in some municipalities prevalence even increased, apparently due to population dynamics and spatial inequalities in the urbanization process, which create conditions favourable to the spread of schistosomiasis and the establishment of new foci (Carmo and Barreto, 1994). The vulnerability of Brazilian towns to schistosomiasis has been reported elsewhere (Mott et al., 1995; Ximenes et al., 2003; Kloos et al., in press). Health facilitybased schistosomiasis and census-based demographic data, although being increasingly used for surveillance purposes as a result of decentralization of the health services in 1999 to the municipalities, can only give a broad indication of spatial and temporal trends. Existing data may be insufficient to construct a surveillance index for serious forms of the disease unless a systematic, standardized data col- lection system is implemented (Barbosa et al., 2005; de Farias et al., 2007).

A considerable number of $S$. mansoni host snail distribution maps have been prepared by epidemiologists and malacologists over the years. The relatively large number of $S$. mansoni intermediate hosts in Brazil, all with different degrees of susceptibility to infection, together with the continued spread of snails into new localities and the large number of potentially suitable snail habitats have fostered a strong and persistent interest in the geographic and temporal distribution of different species of Biomphalaria. Published studies range in scale from the South American subcontinent and Brazil (Paraense, 1986, 2001; Souza et al., 1997) to the State (Bavia et al., 2001; Souza et al., 2001) and community (Souza et al., 1998; Thiengo et al., 2001; Kloos et al., 2004; Tibirica et al., 2006) levels. Most spatial studies mapped snail infections or correlated snail distributions to schistosomiasis prevalence with the objective of identifying highrisk areas, communities and human-water contact sites (Carvalho et al., 2003; Barbosa et al., 2004; Kloos et al., 2004; Araújo et al., 2007). GPS/GISgenerated maps and spatial analyses (Kloos et al., 2004, 2006; Guimarães et al., 2005) are rapidly replacing manually-drawn maps of snail occurrence and infection (Freitas, 1968). The presence of endemic and hyperendemic schistosomiasis in many Brazilian cities (Mott et al., 1995; Ximenes et al., 2003), which usually provide more diverse exposure risk and socio-economic levels than rural communities (Kloos et al., 2006), highlights the need for further studies of urban schistosomiasis.

Spatial analysis of mortality due to schistosomiasis has been hampered by the fact that it is not a reportable disease and deficiencies in the information system. In spite of these impediments, Almeida et al. (2003) found spatial clustering of schistosomiasis-related mortality and spatial associations with socio-economic indicators in the forest zone in the State of Pernambuco, the second highest ranking State in schistosomiasis prevalence in Brazil $(15.2 \%)$, and called for improvements in the infor- 
mation system towards generating more reliable mortality data.

Modeling the distribution of Biomphalaria and schistosomiasis risk by integrating climate, soil, vegetation and socio-economic data using satellitebased RS and GIS systems is a new genre of diseaseecological studies which can contribute to assess the suitability of different regions and localities for snail species (Kristensen et al., 2001). The invasion of different snail hosts and the spread of schistosomiasis into new areas is a major concern in Brazil, where various snail species continue to spread into new areas as a result of dam construction, irrigation development and new settlement projects. By using satellite-derived regional agro-climatic, vegetation and surface temperature maps, together with schistosomiasis prevalence and intermediate host snail distribution data for 270 municipalities in Bahia in a GIS environmental risk assessment model, Bavia et al. (2001) identified several physico-environmental and demographic factors in the distribution of this parasitosis. Currently a similar spatial model is being developed in Minas Gerais (Dutra et al., 2005; Freitas et al., 2005; Silveira et al. 2005). The development of such multivariate models, both at the regional and the community levels, can contribute to identifying high-risk schistosomiasis areas in rapidly developing areas in Brazil and thus facilitate the implementation, management, evaluation and costeffectiveness of control programmes. State-level studies and investigations in other larger geographical areas and research on geographically, climatically, socio-economically and demographically diverse populations may require up-scaling to provide for replication of spatial associations found, consideration of all the major environmental parameters of an area, and the environmental requirements and limits of tolerance of the endemic snail species (Kristensen et al. 2001).

\section{Schistosomiasis control}

Epidemiological and ecological studies using a spatial perspective can effectively contribute to the plan- ning, implementation, surveillance and evaluation of schistosomiasis control programmes. However, few projects have adopted a spatial approach from the beginning as in Rio de Janeiro State, where implementation of a GIS project contributed to the planning, monitoring activities during the surveillance phase of the schistosomiasis control programme at the community level (Moza et al., 2005). The characteristic focality of schistosomiasis distribution, one of the major barriers in the control of schistosomiasis (Crompton et al., 2003), can be efficiently captured and analyzed using spatial tools. Thus, spatial studies can play a major role in the identification, surveillance and control of residual and newly emerging foci in endemic areas experiencing continuous declines in schistosomiasis transmission, also reported from Brazil (WHO, 2001).

Similarly, neither have many studies been carried out on geographic, socio-economic, and health services-related factors with reference to the spatiality of health-seeking behaviour of schistosomiasis patients, nor on the accessibility and utilization of health services. The decentralization of the health services and the correspondingly wider use of municipality health services emphasize the need to identify patterns and constraints in patientaccess to, and utilization of, public health services, following established methodologies (Joseph and Phillips, 1984). In Sumidouro municipality in Rio de Janeiro, Soares et al. (2005) associated difficulty of geographical access of the health services with higher rates of schistosomiasis. Their longitudinal, interdisciplinary study, using qualitative and quantitative methods, including GIS, addressed complex socio-economic, environmental and ecological problems which increased the vulnerability of the population to multi-parasitism and interfered with the health-seeking behaviour and health services utilization of infected persons. Our research group at the Centro de Pesquisas René Rachou has begun a comparative study of the accessibility and utilization of health centers by $S$. mansoni-infected people in a rural area in the northern part of Minas Gerais State. 


\section{Other potential applications of the spatial method}

An excellent review of the literature by Paraense (2001) on the epidemiological and laboratory evidence of variable susceptibility of different species of Biomphalaria, and compatibility between schistosome and snail strains from different parts of Brazil, indicates the need to analyze the spatial distribution of different snail species and their schistosome infectivity status in the evaluation of actual and potential transmission risk. Paraense's finding that the westward diffusion of schistosomiasis in São Paulo State was prevented by the replacement of $B$. tenagophila by $B$. occidentalis in the western part of that state highlights the epidemiological value of longitudinal snail surveys and mapping of the changing distribution of different snail species.

Recent developments in molecular approaches to the identification of $S$. mansoni transmission sites have produced detection systems that are more sensitive than standard screening of snail hosts by cercarial shedding (Melo et al., 2006), which may increase the reliability of identifying transmission sites. Similarly, mapping of genetic markers related to the susceptibility of different species of Biomphalaria in Brazil may provide new information on the macro- and micro-distribution of snail strains susceptible and resistant to $S$. mansoni infection (Oliveira et al., 2005).

In Brazil and other countries with declining schistosomiasis prevalence and intensity, the identification and spatial analysis of the distribution of high-risk populations such as school-aged children not attending school and pre-school children may contribute to surveillance activities and control programmes focused on difficult-to-reach populations and individuals (WHO, 2001; Crompton et al., 2003). Two other understudied and high-risk environments, i.e. large reservoirs (Fernandez et al., 2003) and tourist resorts (Eng et al. 2003; Barbosa et al., 2004; Araújo et al., 2007) require careful surveillance of the intermediate host snail occurrence and human infections. There is no doubt that such studies will be facilitated by the use of GIS and GPS systems.

\section{Conclusions}

Spatial epidemiological and disease ecological studies of intermediate host snails using GIS, GPS and RS tools have increasingly been carried out in Brazil during the last 10 years. They have provided new insights into $S$. mansoni transmission and other information facilitating the development of appropriate and cost-effective interventions. The general decline of schistosomiasis in response to chemotherapy, socio-economic development and improvements in domestic water supply and sanitation on one hand, and the diffusion of the parasite into water development projects and new settlements harbouring, or susceptible to, the spread of intermediate host snails on the other, reflects a dynamic, complex environment amenable to spatial studies and modeling efforts. Accessibility and utilization of the public health services by schistosomiasis patients, which can be evaluated using spatial tools, are urgently needed in view of the focus of the Brazilian schistosomiasis control programme on chemotherapy (WHO, 2001). The identification of high-risk individuals and groups, modeling of the distribution of snail intermediate host snails and transmission risk, as well as the development of new molecular approaches to assessing transmission potential are of particular interest for control purposes. However, they will require reliable data and the studies must be carried out at scales and in temporal frames appropriate for control programmes to be of optimal usefulness.

\section{Acknowledgements}

We thank the Editor of Memórias do Instituto Oswaldo Cruz for permission to reprint the figure.

\section{References}

Almeida A, Resendes AP, Costa MJ, Alarta JES, Ilona MB, Nascimento RS, Rogerio S, 2003. Analysis of spatial distribution of mortality from mansonic schistostosomiasis in municipalities of Pernambuco State in the period 1997- 
2000. Abstracts of the $9^{\text {th }}$ International Symposium on Schistosomiasis, Salvador, Brazil, 55 p.

Araújo KC, Resendes APC, Souza-Santos R, Silveira JC Jr, Barbosa CS, 2007. Spatial analysis of Biomphalaria glabrata foci and human cases of mansoni schistosomiasis in Porto de Galinhas, Pernambuco State, Brazil, in the year 2000. Cad Saúde Públ 23, 409-417.

Barbosa CS, Araújo KC, Antunes L, Favre T, Pieri OS, 2004. Spatial distribution of schistosomiasis foci on Itamaracá Island, Pernambuco, Brazil. Mem Inst Oswaldo Cruz 99, 79-83.

Barbosa CS, Favre T, Araújo KC, Callaou AC, Wanderley TN, Pieri O, 2005. Epidemiological evaluation of schistosomiasis in schoolchildren of rural Pernambuco, Brazil. Abstracts of the $10^{\text {th }}$ International Symposium on Schistosomiasis. Belo Horizonte, Brazil, 178 p.

Barreto ML, 1993. The dot map as an epidemiological tool: a case study of Schistosoma mansoni infection in an urban setting. Int J Epidemiol 22, 731-741.

Bavia ME, Malone JB, Hale L, Dantas A, Marroni A, Reis E, 2001. Use of thermal and vegetation index data from Earth observing satellites to evaluate the risk of schistosomiasis in Bahia, Brazil. Acta Trop 79, 79-85.

Bethony J, Williams JT, Brooker S, Gazzinelli A, Gazzinelli MF, LoVerde PT, Correa-Oliveira R, Kloos H, 2004. Exposure to Schistosoma mansoni infection in a rural area in Brazil. Part III: household aggregation of water contact behavior. Trop Med Int Health 9, 381-389.

Bethony J, Williams JT, Kloos H, Blangero J, Alves-Fraga L, Buck G, Michalek A, Williams-Blangero S, LoVerde PT, Correa-Oliveira R, Gazzinelli A, 2001. Exposure to Schistosoma mansoni infection in a rural area in Brazil. II. Household risk factors. Trop Med Int Health 6, 136-145.

Brooker S, Michael E, 2000. The potential of geographical information systems and remote sensing in the epidemiology and control of human helminth infections. Adv Parasitol 47, 246-288.

Carmo EH, Barreto ML, 1994. Schistosomiasis in Bahia, Brazil: historical trends and control measures. Cad Saúde Púb 10, 425-439.

Carvalho OS, Scholte CRG, Menezes GMA, Drumond SC, Caldeira RL, 2003. Spatial distribution of Biomphalaria glabrata and schistosomiasis prevalence in the state of Minas Gerais. Proc. $9^{\text {th }}$ International Symposium on
Schistosomiasis, Salvador, Brazil, $156 \mathrm{p}$.

Crompton DWT, Engels D, Montresor A, Neira L, 2003. Action starts now to control disease due to schistosomiasis and soil-transmitted helminthiasis. Acta Trop 86, 121-124. de Farias LM, Resendes AP, Sabroza PC, Souza-Santos R, 2007. Preliminary analysis of the information system in the Brazilian schistosomiasis control program, 1999-2003. Cad Saúde Púb 23, 235-239.

Dutra LV, Freitas CC, Moura ACM, Guimarães RJPS, Freitas C, Amaral RS, Drummond SC, Scholte RGC, Melo GR, Guerra M, Calvalho OS, 2005. Development of an information system for the study, planning and control of schistosomiasis in the State of Minas Gerais. Abstracts of the $10^{\text {th }}$ International Symposium on Schistosomiasis, Belo Horizonte, Brazil, 77 p.

Eng MJ, Amorim A, Schall VT, 2003. Rural tourism as risk factor for the transmission of schistosomiasis in the State of Minas Gerais-Brazil. Abstracts of the $9^{\text {th }}$ International Symposium on Schistosomiasis, Salvador, Brazil, $145 \mathrm{p}$.

Fernandez MA, Thiengo SC, Boaventura FF, Mattos AC, 2003. Studies preventing the installation of schistosomiasis foci in two great dams in central Brazil. Abstracts of the $9^{\text {th }}$ International Symposium on Schistosomiasis, Salvador, Brazil, 148 p.

Freitas CC, Guimarães RJPS, Dutra LV, Moura ACM, Amaral RS, Drummond SC, Scholte RGCS, Guerra M, Freitas CR, Carvalho OS, 2005. Análise e estimativa da prevaléncia da esquistossomose para a estado de Minas Gerais usando regressão múltipa com dados sócio-ambientais. Abstracts of the $10^{\text {th }}$ International Symposium on Schistosomiasis, Belo Horizonte, Brazil, 120 p.

Freitas JR, 1968. Curso sobre ambiental da esquistossomose. Universidade Federal de Minas Gerais and Oficina Médica da Saúde, Belo Horizonte, Brazil.

Gazzinelli A, Bethony J, Fraga LA, LoVerde PT, CorreaOliveira R, Kloos H, 2001. Exposure to Schistosoma mansoni infection in a rural area of Brazil: I. Water contact. Trop Med Int Health 6, 126-135.

Gazzinelli A, Hightower A, LoVerde PT, Haddad JPA, Pereira WR, Bethony J, Correa-Oliveira R, Kloos H, 2006. The spatial distribution of Schistosoma mansoni infection before and after chemotherapy in the Jequitinhonha Valley in Brazil. Mem Inst Oswaldo Cruz 101, 63-71.

Guimarães RJPS, Freitas CC, Dutra LV, Felgueiras CA, 
Moura ACM, Amaral RS, Drummond SC, Scholte RGC, Freitas CR, Carvalho OS, 2005. Distribuição espacial dos moluscos do gênero Biomphalaria na bacia do Rio São Francisco-MG usando krigeagem por indicacão. Abstracts of the $10^{\text {th }}$ International Conference on Schistosomiasis, Belo Horizonte, Brazil, $121 \mathrm{p}$.

Joseph AE, Phillips DR, 1984. Accessibility and utilization: geographical perspectives on health care and delivery. London, Harper \& Row.

Katz N, 1998. Schistosomiasis control in Brazil. Mem Inst Oswaldo Cruz 93, 33-35.

Kloetzel K, 1989. Schistosomiasis in Brazil: does social development suffice? Parasitol Today 5, 388-391.

Kloos H, Correa-Oliveira R, Gazzinelli A. Socioeconomic studies of schistosomiasis in Brazil: a review. Acta Trop, submitted.

Kloos H, Gazzinelli A, Correa Oliveira R, 2001. Nova União village, Brazil - the impact of a new water supply. Waterlines 19, 15-18.

Kloos H, Gazzinelli A, Van Zuyle P, 1998. Microgeographical patterns of schistosomiasis and water contact behavior: examples form Africa and Brazil. Mem Inst Oswaldo Cruz 93, 37-50.

Kloos H, Passos LKJ, LoVerde P, Correa Oliveira P, Gazzinelli A, 2004. Distribution and Schistosoma mansoni infection of Biomphalaria glabrata in different habitats in a rural area in the Jequitinhonha Valley, Minas Gerais, Brazil: environmental and epidemiological aspects. Mem Inst Oswaldo Cruz 99, 673-681.

Kloos H, Rodrigues JCAP, Prereira WR, Valesquez-Melendez G, LoVerde P, Correa Oliveira R, Gazzinelli A, 2006. Combined methods for the study of water contact behavior in a rural schistosomiasis-endemic area in Brazil. Acta Trop 97, 31-41.

Kristensen TK, Malone JB, McCarrol JC, 2001. Use of satellite remote sensing and geographic information systems to model the distribution and abundance of snail intermediate hosts in Africa: a preliminary model for Biomphalaria pfeifferi in Ethiopia. Acta Trop 79, 73-78.

Kvale KM, 1981. Schistosomiasis in Brazil: preliminary results from a case study of a new focus. Soc Sci Med 15D, 489-500.

Machado PA, 1982. The Brazilian program for schistosomiasis control. Am J Trop Med Hyg 31, 76-86.
Malone JB, Bergquist NR, Huh OK, 2001a. A global network on schistosomiasis information systems and control of snail-borne diseases. Acta Trop 79, 1-106.

Malone JB, Bergquist NR, Huh OK, Bavia ME, Bernardi JM, El Bahy MM, Fuentes MV, Kristensen TK, McCarroll JC, Yilma JM, Zhou XN, 2001b. A global network for the control of snail-borne disease using satellite surveillance and geographic information systems. Acta Trop 79, 7-12.

McClennon JA, King CH, Muchiri EM, Kariuki HC, Ouma JH, Mungal P, Kitron U, 2004. Spatial patterns of urinary schistosomiasis infection in a highly endemic area of coastal Kenya. Am J Trop Med Hyg 70, 443-448.

Meira JA, 1949. Schistosomiasis: a survey of its distribution in Brazil. Bull World Health Organ 2, 31-37.

Melo FL, Gomes AL, Barbosa CS, Werkhauser RP, Abath FG, 2006. Development of molecular approaches for the identification of transmission sites of schistosomiasis. Trans R Soc Trop Med Hyg 100, 1049-1055.

Morel C, 2001. Foreword. Acta Trop 79, 1-2.

Mott KE, Nuttal I, Cattani P, 1995. New geographical approaches to control some parasitic diseases. Bull World Health Organ 73, 247-257.

Moza PG, Benevente EV, dos Santos GT, 2005. Abstracts of the $10^{\text {th }}$ International Symposium on Schistosomiasis. Belo Horizonte, Brazil, 131 p.

Oliveira ALD, Gonçalves RD, Levada PM, ZanottiMagalhães EM, Magalhães L, Spada RGM, Ribeiro-Paes JT, 2005. Differential gene expression in Biomphalaria tenagophila strains susceptible to the larval forms of Schistosoma mansoni. Abstracts of the $10^{\text {th }}$ Symposium on Schistosomiasis, Belo Horizonte, Brazil, 195 p.

Paraense WL, 1986. Distribucão dos caramujos no Brasil. In: Reis FA, Faria J and Katz N (eds.), Modernos Conhecimentos sobre a Esquistossomose Mansônica. Suplemento dos Anais de 1983/1984. Academia Mineira de Medicina, Belo Horizonte, Brazil, 117-128.

Paraense WL, 2001. The schistosome vectors in he Americas. Mem Inst Oswaldo Cruz 96, 7-16.

Resendes AP, Souza-Santos R, Barbosa CS, 2005. Hospitalization and mortality from mansoni schistosomiasis in the state of Pernambuco, Brazil, 1992-2000. Cad Saúde Púb 21, 1392-1401.

Savioli L, Albonico M, Engels D, Montresor A, 2004. Progress in the prevention and control of schistosomiasis and soil- 
transmitted helminthiasis. Parasitol Int 53, 103-113.

Silveira J, Berger T, Hacon S, Soares MS, Cunha RA, Oliveira TF, Buss DF, Ribeiro LL, Argento R, Gracie R, Schutz G, 2005. Abordagem ecosistêmica em saúde e controle da esquistossomose no Alto Santa Maria (Santa Maria de Jetibá, ES, Brasil). Abstracts of the $10^{\text {th }}$ International Symposium on Schistosomiasis, Belo Horizonte, Brazil, 243 p.

Soares MS, Barreto MGM, Gentile R, Gonçalves MML, D’Andréa PS, Cunha RA, Oliveira TF, Gusmão M, Rey L, 2005. Schistosomiasis and geohelminthiasis control in the Municipality of Sumidoura (RJ, Brazil): perspectives after 15 years of investigation. Abstracts of the $10^{\text {th }}$ International Symposium on Schistosomiasis, Belo Horizonte, Brazil, 244 p.

Souza CP, Caldeira RL, Drummond SC, Melo AL, Guimarães CT, Soares DM, Carvalho OS, 2001. Geographic distribution of Biomphalaria snails in the state of Minas Gerais, Brazil. Mem Inst Oswaldo Cruz 96, 293-302.

Souza CS, Lima L, 1997. Moluscos de Interesse Parasitológico do Brasil. Ministry of Health, Centro de Pesquisas René Rachou, Belo Horizonte, Brazil.

Souza CP, Lima LC, Jannoti-Passos SSF, Guimarães CT, Vieira IUBF, Mariano Junior R, 1998. Moluscos limnicos da microregião de Belo Horizonte, MG, com enfase nos vec- tores de parasitoses. Rev Soc Bras Med Trop 31, 449-456. Thiengo SC, Fernandez MA, Boaventura MF, Grault CE, Silva HFR, Mattos AC, Santos SB, 2001. Freshwater snails and schistosomiasis in the State of Rio de Janeiro, Brazil: IMetropolitan Mesoregion. Mem Inst Oswaldo Cruz 96, 177-184.

Tibirica SH, Bessa EC, Mittherofhe A, Castro MF, Carvalho Odos S, Caldeira RL, Pasos LK, Mattos AM, Pinheiro LS, Silva DS, Bastos FO, Andreoli GQ, Bonato GR, Coimbra ES, 2006. Biomphalaria spp. (Preston, 1910) snails in the municipality of Juiz de Fora, Zona da Mata Mineira mesoregion, Minas Gerais, Brazil. Mem Inst Oswaldo Cruz 101, 179-184.

Woolhouse MEH, Watts CH, Chandiwana SK, 1991. Heterogeneities in transmission rates and the epidemiology of schistosome infection. Proc R Soc London Ser B 245, 109-114.

WHO, 2001. Report of the WHO informal consultation on schistosomiasis in low transmission areas: control strategies and criteria for elimination. WHO document WHO/CDS/CPE/SIP/2001.1. Geneva.

Ximenes R, Southgate B, Smith PG, Neto LG, 2003. Socioeconomic determinants in an urban area in the Northeast of Brazil. Pan Am J Publ Health 14, 409-421. 